\title{
Developing a Profiling Tool Using a Values Approach to School Renewal
}

\author{
Raymond Brown \\ Griffith University \\ Harry Kanasa \\ Griffith University
}

\author{
Deborah Heck \\ University of the Sunshine
}

Coast

\author{
Donna Pendergast \\ Griffith University
}

Ann Morgan

Marlene Moore Flexi Schools

Network

\section{STRUCTURED ABSTRACT}

\section{Intellectual Context}

This article describes a four-year project spanning the development and trialling of the School Renewal Profiling Tool (SRPT). The development of the SRPT was informed by a sociocultural theoretical framework that built on the work of Harré's (1984) concept of the Vygotskyian space (Vygotsky's, 1987) and Lave and Wenger's (1991) notion of situated learning to explore a learning based approach to school renewal.

\section{Purpose}

The purpose of this article is to outline the evidence based development of a learning approach to school renewal that employs information from key members of a school community (teachers, parents, students) to promote school based discussions about school renewal.

\section{Setting}

The study took place in an independent system of Catholic schools. Schools in this tradition have an enduring history in the development of Catholic Education in Australia, New Zealand, Papua New Guinea, India, Africa, Europe and the Americas.

\section{Research Design}

The study employed a qualitative sociocultural design focused on generating narratives that could be used to describe the school as a community of practice and the development of a 
valid and reliable School Renewal Profiling Tool (SRPT) that provides an empirical picture of a school's culture and practice.

\section{Data Collection and Analysis}

Data collection included school visitations, classroom observations, in-depth interviews, and publically available school documentation and data gathered from a case study site, a coeducational secondary college located in the centre of a metropolitan city. Data collected were subjected to thematic analysis and Principal Components Analysis (PCA). Data gathered from the SRPT items were then presented to the school community in the form of a collated report for feedback and school renewal purposes.

\section{Findings}

Findings suggest that the SRPT has the potential to capture local ways of knowing and doing as resources to promote organisational school renewal through reflecting individual perceptions of participation in collective practice.

\section{Conclusions}

The research surrounding the development of the SRPT contributes to the field of school renewal in two distinct ways. First, the development of the SRPT offers an approach to school renewal that focuses on the values upon which a school community is based. Second, the SRPT avoids the difficulty of what Fielding (2004) refers to as 'speaking about and for others' where the original thoughts of respondents are couched in the language and values of the researcher.

\section{EXECUTIVE SUMMARY}

School renewal with the agenda to achieve higher student outcomes is a feature of contemporary times. In order to be effective renewal needs to engage parents, teachers and students, key stakeholders of every school community. The research reported here embeds school renewal in changes that take place in school and classroom cultures at the level of 
beliefs, values and behaviours for the purpose of outlining a sociocultural approach to school renewal based on individual and collective participation in the practices of a school community. Specifically the purpose of this article is to describe a four-year project spanning the development and trialling of a School Renewal Profiling Tool the SRPT.

The development of the SRPT took place in an independent system of Catholic schools. Schools in this tradition have an enduring history in the development of Catholic Education in Australia and have partner schools in New Zealand, Papua New Guinea, India, Africa, Europe and the Americas. They also offer a flexible education for young people disengaged and disenfranchised from the mainstream education system who are diverse in terms of socioeconomic status, ethnicity and geographical location.

Employing a qualitative design the research focused on fulfilling two methodological aims. First, to generate narratives that tell the story of a school's practices that could be used to describe the school community. Second, to develop a valid and reliable School Renewal Profiling Tool (SRPT) that provides an empirical picture of a school's culture and practice. In order to achieve the first aim, the researchers undertook school visitations, classroom observations, in-depth interviews, and studied publically available school documentation to gain a rich description of individual and public representations of eight school sites (three mainstream and five alternative education schools) representative of the geographical, economic and student diversity of the independent system of schools that partnered the research. These data were subjected to thematic analyses and led to the development of school narratives that formed the basis of the design of the SRPT survey items. In order to achieve the second aim, an appropriate pilot study site, a co-educational secondary college located in the centre of a metropolitan city, was administered the SRPT survey items. The survey items for the key stakeholder groups (teachers, parents, students) were tailored, in terms of the terminology used, to ensure that the survey items used language that was most 
familiar within this school's particular context. Data gathered were subjected to Principal Components Analysis (PCA) and qualitative thematic analysis for the purpose of refining the SRPT. Data gathered from the SRPT items were then presented to the school community in the form of a collated report for feedback and school renewal purposes.

Findings suggest that the SRPT has the potential to capture local ways of knowing and doing as resources to promote school renewal through reflecting individual perceptions of participation in the collective practices of a school. In particular it was found that the SRPT has potential to provide empirical data that may help school communities to look beyond student achievement on external measures to reflect on the organisational categories within their schools (e.g., Culture, Learning, Leadership, Formation and Community). Analyses of data from the pilot phase of the SRPT suggest that the SRPT has the potential to counter typical constructions of teacher and student in ways that promote teacher and student voice, that is, the means through which teachers and students make their thoughts known, represent their experience, and involve themselves in life's decisions.

The research surrounding the development of the SRPT contributes to the field of school renewal in two distinct ways. First, the development of the SRPT offers an approach to school renewal that focuses on the values upon which the school community is based. Insights gained from the implementation of the SRPT may then be interpreted in the light of a school's mission and vision and lead, eventually, to more open and equitable forms of dialogue between parents, teachers and students, an endeavour worth pursuing in terms of school renewal and transformation. Second, the fact that data from the SRPT are presented to school communities in a de-identified form ensures that the SRPT avoids the difficulty of teachers, parents and students original thoughts about the school community being couched in the language and values of the researcher. In so doing, the SPRT offers a tool to assist 
school communities to self-identify and develop their own solutions to challenges that limit their capacity to engage in meaningful school renewal.

The practical implications of the development of the SRPT for school renewal are substantial. Although the place of values in school renewal has gained currency over the last decade, there is limited research available about the approaches taken by schools to incorporate values into their school renewal processes. The development of a values approach to school renewal, as experienced in the SRPT, provides schools with a communal approach to school renewal that reflects on values as lived in school contexts. Armed with an effective tool to assist parents, students and teachers to reflect on values as lived in school contexts, educators will be better able to conduct research on how best to involve values, as reflected in school vision and mission statements, in a process of school renewal. A form of school renewal focused on fostering school contexts that promote community building, that guide improvements in student learning and that promote increased satisfaction by important stakeholder groups.

\section{Overview of the Study}

School renewal with the agenda to achieve higher student outcomes is a feature of contemporary times. In their report, How the world's most improved school systems keep getting better, Mourshed, Chijioke and Barber (2010) outline how twenty education systems around the world improved their performance. They point to the complexity of school renewal, noting that starting points are different, contexts are unique, choices are vast and there is no formula for making decisions along the way. More recently, in 2015 the OECD released a report investigating the effectiveness of reform in education. This investigation of

more than 450 reforms over 8 years in OECD countries revealed that in order to be effective, reforms need to be "designed around students and learning, build teachers' capacity, and engage all stakeholders" (OECD, 2015:2). In this study we identify that school renewal is 
embedded in changes that take place in school and classroom cultures at the level of beliefs, values, attitudes and behaviours (Cavanagh \& Waugh, 2004). This is in contrast to the notion of school reform developed around the replication of whole school approaches to management and instruction that focus on accountability measures informed by policy, practice, and research, seeking to identify measures of school effectiveness and improvement (Comber \& Nixon, 2009). This accountability metric approach to school reform is located in a paradigm that views learning as an individual activity that is measureable through standardised performance measures (see Bowen, Rose, \& Ware, 2006). Important as this approach may be, it is insufficient to bring about school renewal (Peck, Gallucci, Sloan, \& Lippincott, 2009) which we argue requires individual learning to be viewed as both process and product of participation in cultural practice (Lave \& Wenger, 1991). A sociocultural approach to school renewal focuses on individual and collective participation in the practices within social and cultural contexts while the school reform agenda is focussed on individual and collective accountability (Villegas \& Lucas, 2002). The shift from a school reform towards a school renewal approach provides fertile theoretical ground for developing a values based approach to school renewal.

The purpose of this article is to outline the development of an approach to school renewal that is based on a sociocultural notion of mediated practice. A participatory approach was used where practices such as those associated with the collective enterprise of learning are viewed as being mediated by tools that bridge the private and public as well as the individual and the collective divide (Harré, 1984). In order to do this we position the knowledge and practices of the community as being resources for learning that inform renewal (Brown \& Duguid, 1991). The work was conducted in the context of a faith based school system and hence was informed by a commitment to a charter of values referred to as 
'The Charter,' a proclamation of values that guide the vision and mission of each school within the system.

\section{Study Context}

The study took place in an independent system of Catholic schools. Schools in this tradition have an enduring history in the development of Catholic Education in Australia. Over the years many schools originally founded in this tradition have amalgamated with other schools, been handed over to the Church or have closed. Schools in this tradition seek to build a relationship with other Catholic Schools that see their mission in association with their 'Charter'. Schools with no historical link to the 'Charter' but which desire a connection to this tradition of schooling are included through Association. Associate schools are invited to participate in formation and other programs offered by schools in this tradition and have access to publications and resources. Schools in this tradition have partner schools in New Zealand, Papua New Guinea, India, Africa, Europe and the Americas. They also offer a flexible education for young people disengaged and disenfranchised from the mainstream education system who are diverse in terms of socioeconomic status, ethnicity and geographical location.

This system of education, in 2014, consisted of 48 mainstream schools enrolling over 35,000 students, through all states and territories of Australia. In addition to these mainstream schools there were 14 alternative education schools that provide young people with an opportunity to re-engage in education in a flexible and supported learning environment. One school site, within this system of schooling, engaged in the piloting and development of the

School Renewal Profiling Tool (SRPT). A further seven sites engaged with the SRPT as a means to access data from students, parents and teachers for the purpose of school renewal.

\section{Conceptual Framework}


An understanding of the culture of an organisation within a system of education, that is, the physical (e.g., location), psychological (e.g., morale), and institutional (e.g., beliefs) attributes of a school (see Lezotte, Hathaway, Miler, Passalacqua, \& Brookover, 1980), may be supported through gaining a public representation of the organisation from teachers, administrators and other stakeholders (Clifford, Menon, Gangi, Condon, \& Hornung, 2012). The place of such a public representation in a model of participatory learning may be achieved through making explicit elements of the Vygotskian space model, as they might be envisioned in Wenger's (1998) model of social learning.

Harré (1984) provided a framework, the Vygotskian Space, that has been used to characterise how individual development is achieved through collective practice (Harré, 1984), and to trace individual and collective participation in social processes related to professional development (Gallucci, 2008). The Vygotskian space incorporates dimensions that encompass individual and collective practice within the realm of the private and public. This mode provides a way of looking at phases of learning as a process where cultural practices are appropriated by individuals, internalised through the lens of individual needs, and then made public in ways that can be appropriated by others (Galluci, 2008).

This approach allows us to view learning in an holistic sense, as being cyclical and evolutionary, as being both cumulative and transactional, and fulfils the purpose of being a model of individual learning (Galluci, 2008; Harré, 1984).Through exploring the learning process as represented by Harré and Galluci we realised that this model would be sufficient for an acquisition approach to learning, however for a participatory approach to learning, we needed to open the Vygotskian Space (see Vygotsky, 1987) to include the relationship between the collective and the private; the private and the individual; and the individual and the public. 
One way of interpreting the mediation of the personal and the public is provided through Wertsch and Rupert's (1993) account of 'mediated agency'. The notion of 'mediated agency' extends Vygotsky's 'general genetic law of cultural development' and revolves around the 'irreducible tension' manifested between a person on the one hand and the mediational means that he/she employs to have access to a more public other (Wertsch \& Rupert, 1993). Through interpreting the relationship between the personal and the public in terms of 'mediated agency', Wertsch and Rupert position the personal within systems of collective activity that are culturally and historically situated. From this point of view, issues which affect the sociocultural organisation of a collective such as schooling (e.g., issues related to power and authority, membership and identity, consensus and diversity, and commitments which privilege certain ways of thinking and acting) are seen as essential aspects of personal functioning within the public sphere. A key theoretical claim of 'mediated agency' is, therefore, that personal action within the public domain is fundamentally shaped by mediational means.

In terms of the Vygotskian Space as proposed by Harré (1984), a practice such as 'schooling' may elicit a few personal items of information such as the name of a school, teacher, personal experience, or favourite subject, from a person not publicly involved with a school community. However, mention the term 'schooling' to a practising teacher and one may experience a very long account of that person's recall of factual and affectual information relating to his or her experience of schooling. For Vygotsky, this phenomenon of recall is explained by the socio-historical evolution of the meaning and sense of the practice of 'schooling', that is, as a practice such as 'schooling' passes through a teacher's enculturation it absorbs all the diversity contained within the contents of its experience and the public situations in which the person experienced those contents. As such, after time, the practice of 'schooling' may come to be equated by the teacher with an entire education 
collective and with the feelings this collective evokes. Hence, for a person who is a practising teacher, the practice of 'schooling' becomes a powerful cultural tool that influences his or her membership within a school community. It is in this way that a cultural practice may be appropriated, internalised and made public. In order to explore further a participation approach to learning we turned to Wenger (1998) and his description of a social theory of learning to provide a lexicon for the reformulation of a Vygotskian framework in light of the gaps identified, an approach that would provide a mechanism for exploring participatory learning within the collective practices of an organisation.

Wenger's notion of community of practice offers a framework for understanding participatory interactions and engagement in educational communities of practice. Gaining insights into how culture and practice in school communities can be renewed, requires that diverse perspectives from a range of stakeholders including teachers, parents and students are included. As diverse perspectives are given consideration regardless of whether they belong to stakeholders whose participation is central or peripheral (Wenger, 1998), shared meaning can be cultivated. The exploration of divergent responses between participant groups creates space for dialogic reflective processes that offer opportunities to create new learning and shared meaning. By considering diverse and at times conflicted perspectives of those within the community, the responses of all stakeholders are validated. This approach complements other Vygotskian space perspectives that acknowledge the influence between parties as being multi-directional rather than uni-directional (Del Rio \& Alvarez, 2007; Goos, Galbraith, \& Renshaw, 2002; Harland, 2003), thus reinforcing the value of different kinds of participatory engagement. Whilst such processes may not resolve differential power dynamics, they offer processes that make room for a range of participatory responses to make power dynamics more visible. 
The SRPT offers the possibility for members to address unequal power dynamics typically inherent in their school communities, by giving voice to those who are often overlooked. By highlighting statistically significant differences between responses from different stakeholder groups, the tool offers an opportunity to explore and understand what such differences mean within the community. Trying to understand the reasons for different perspectives rather than highlighting 'who' or 'what' is 'right' or 'wrong', provides the opportunity for informed and meaningful dialogic interactions. Such interactions have the potential to shape the renewal of culture within the school community in constructive and participatory ways. These processes can make more visible inherent power dynamics within school communities of practice.

The concept of 'community of practice' has been described as "a set of relations among persons, activity, and world, over time" and as being "an intrinsic condition for the existence of knowledge ..." (Lave \& Wenger, 1991: 98). As such, the notion of a 'community of practice' is concerned with the learning that people negotiate themselves, that mediates their work, and that connects to membership in other communities of practice (Wenger, 1998). In other words, communities of practice are about people engaging in practices mediated by social processes that produce agreed upon public representations of knowing and doing. Learning, therefore, results from engagement in social contexts and is mediated by ways of knowing, doing and valuing that are culturally situated. In this process personal meaning is shared and made public in a context of relationships to others, to activity, and to the world and may be transformed over time to show both congruence with and critique of the collective ways of knowing, doing and valuing (Lave \& Wenger, 1991).

The four constructs of identity, practice, meaning and community are the essential components of Wenger's social theory of learning. These four essential components of Wenger's model are defined in relation to learning in the following ways: identity (learning 
as becoming); practice (learning as doing); meaning (learning as experience); and community (learning as belonging) (1998: 5). In the development of the School Renewal Profiling Tool (SRPT), the intersection of the four components of the community of practice model, provided a lens to understand and explore shared meaning making processes. This occurred as diverse and multiple stakeholder perspectives were invited and considered as valid contributions to inform the renewal of the learning community. As such, profiling is identified here as a mechanism for developing individual or group profiles that allow, in this instance, school communities to identify patterns in increasingly large data sets that support the discernment of information and the construction of knowledge into formats that can be understood by the community (Hildebrandt, 2008). This notion of profiling provides a way of refocusing the dimensions of personal, collective, private, and public learning within a theory that identifies meaning making, community, identity, and practice. For our study, this sociocultural theoretical lens underpins our learning approach to school renewal and facilitated the design of a research approach that explored participatory learning within the collective practices of an organisation that led to the development of the 'School Renewal Profiling Tool' (SRPT).

In its design and development, the SRPT not only reflects the 'Community of Practice' dimensions of meaning making, community, identity, and practice, but also the limitations of these dimensions as may be played out in a school community. For example, the SRPT is comprised of three surveys aligned with the language of teachers, parents and students to recognise the network of communities that make up a school community. The SRPT has been designed to be responded to anonymously, online, thus recognising the power differential of the diverse groups that make up the school. Finally, the SRPT has been designed with the expectation that it may be provided to school communities on a regular 
basis (every 2 to 3 years), thereby recognising the ever changing nature of a school community and the evolving forms of participation within it.

The SRPT speaks to instructional models such as the Productive Pedagogies (Lingard, Ladwig, Mills, Hayes, Luke, Gore, \& Christie, 2001) and a Pedagogy of Ethical Care (Noddings, 2003), and forms the basis on which to design and reflect upon values and other cultural tools within a framework of school renewal. The Productive Pedagogies framework was developed and used as part of a whole system reform process which set out to improve the teaching and learning effectiveness of classrooms in Queensland, Australia through the implementation of the model to guide teacher practice. The framework consists of the following four dimensions that collectively are intended to draw attention to important elements of effective and intellectually challenging learning: intellectual quality; connectedness; supportive classroom environment; and valuing and working with difference. The need to develop tools which provide schools with a means of self-reflection is given currency by the OECD (2015), Education Policy Outlook 2015: Making Reforms Happen that states: "[E]ffective school self-evaluation contributes to school improvement and is not simply an exercise in compliancy" (OECD, 2015:131).

The SRPT is an online survey that is not designed to solve problems associated with school renewal; instead, the tool provides the groundwork for school communities to selfidentify and develop their own solutions to challenges that limit the capacity of school communities to engage in meaningful school renewal. This can be achieved by the SRPT providing empirical data from individuals to create a collective view of what the school values. This collective view then provides an opportunity for a conversation between stakeholders to change or consolidate existing initiatives or to identify the need for new initiatives, and provides a mechanism for ongoing data collection and reflection. Data are 
provided through stakeholder (student, parent, teacher) responses to 54 Likert type items that employ a four point scale from strongly disagree to strongly agree.

In the following sections of this article we firstly outline the process employed for the collection of school observations that led to the development of school narratives that formed the basis of the design of the SRPT items, secondly, we outline the process that led to the collation of school narratives and their translation into items that suit the needs of audience stakeholders, and thirdly we outline the process used to examine the relative fit of the items with the conceptual model that informed its development. Finally, we examine the construct validity of the SRPT with respect to stakeholders' perceptions about the school community. We conclude by discussing the implications of our results for the practice of school renewal.

\section{Methodology}

This research was designed to fulfil two methodological aims. First, to generate narratives that tell the story of a school's practices that could be used to describe the school as a community of practice. Second, to develop a valid and reliable School Renewal Profiling Tool (SRPT) that provides an empirical picture of the school culture and practice. In order to achieve the first aim, the research undertook school visitations, classroom observations, indepth interviews, and studied publically available school documentation to gain a rich description of individual and public representations of eight school sites (three mainstream and five alternative education schools) representative of the geographical, economic and student diversity of the independent system of schools that partnered the research. These forms of data collection have been used successfully by Lave and Wenger (1991) to describe a variety of communities of practice, by Gallucci (2008) to observe the links between professional learning and organisational support, and by Gutiérrez and Stone (2002) to tell the stories of different communities of practice.

The development of school narratives 
In sociocultural terms, meaning is co-constructed, therefore research cannot simply look at one aspect of a school, for example, the school vision statement. Instead it must look at the culture of the school as expressed in classrooms, school grounds, staffrooms and other collective spaces. In order to facilitate this co-construction of meaning, an observational schedule that related to school culture was developed. This schedule was developed using the categories of the 'The Charter' that guided practice in the independent system of Catholic schools being observed. 'The Charter' is a proclamation of values that must be demonstrated in the accreditation process of this independent school system. It identifies 11 value categories that together form a values framework. Each category is accompanied by descriptors that identify the value in a school setting. This framework speaks to the Melbourne Declaration on Educational Goals for Young Australians (MCEETYA, 2008) and encapsulates the values for Australian schooling, as expressed in the National Framework for Australian Schools (Australian Government, 2005). As such a study of 'The Charter' was considered by the system of independent schools to be highly significant for their purposes of school renewal at this time. It is also argued by researchers such as Halstead and Taylor (2000) that a communal approach that reflects on values as lived in communal contexts can be an effective means of bringing about school renewal. The categories of 'The Charter' related to Teaching, Spirituality, Community, and Justice. These categories were further subdivided into sub-categories with descriptors and rating scales to facilitate the observation process (see Table 1 and Figure 1).

\section{\{INSERT TABLE 1 HERE $\}$}

As can be seen in Table 1, the categories, sub-categories and descriptors were tailored to cater for the context of the Catholic system of schools being observed. Figure 1 provides the observational sheet used for the sub-category 'community.' This observational sheet is typical of the format used for recording the observation of each of the sub-categories. 


\section{\{INSERT FIGURE 1 HERE $\}$}

As can be seen in Figure 1, each observational sheet presented a score from 1 to 5 with 1 representing no evidence of the sub-category being observed and 5 representing strong evidence of the sub-category being observed. Observers were required to independently score their observations about each category and come together to provide evidence for their score and to agree on the best score that represented the observations of that category for a particular observation session. Observations were conducted by at least two independent researchers at any one time in places where participants felt comfortable to have their interactions observed. This enabled inter-rater reliability for these data sets (Syed \& Nelson 2015). Each observation lasted for approximately the length of a school event (e.g., observations of lessons usually lasted for 40 minutes, observations of school assemblies usually lasted for 15 minutes). Observations occurred over the duration of two school days at each site and numbered six, approximately, at each site. Every effort was made at each site to observe a Mathematics/Numeracy lesson, an English/Literacy lesson, Social Studies/Religion lesson, a school assembly, a staff meeting/gathering and playground interactions. A total of 54 observations were made across eight school sites. The observational schedule used by researchers and the method adopted to record observations ensured that students' experiences at the classroom level (e.g., a math lesson) and at the school level (e.g., playground interactions) informed the development of the school narratives which, in turn, informed the development of the SRPT.

Observations at the eight school sites also included in-depth interviews to gain a rich description of the life of the school. Interview questions were designed to relate to the 'observational schedule'. This schedule situated the interview questions (see Figure 2 for a sample of questions used) within broad categories relating to teaching, spirituality, 
community, and justice. The schedule allowed questions to be asked according to the context of the school that was being observed, thus allowing the story of the interviewees to be told, but ensuring that information was provided to assist in explicating the similarities and differences across school contexts. Interviews were conducted by researchers in places where interviewees felt comfortable to tell their story. Each interview lasted for approximately 30 minutes, was audio recorded and transcribed for analysis. Every attempt was made to interview the teachers of the lessons observed, a member of the leadership team, and a member of the support team at each school site. This resulted in a total of 37 interviews across the eight school sites taking place.

\section{\{INSERT FIGURE 2 HERE $\}$}

Data gathered from observations and interviews, along with interrogations of school web sites, contributed to the development of school narratives that were shared with the respective school site. In authoring each school narrative, a coherent process was followed. After the school site visit a debriefing meeting was held where the research team explored the data set including the observational schedule, data gathered from observations, interviews and the school web-site. The research team then came together to author a draft of the school narrative. This narrative was based upon and contained summary analyses of data sets relating to the broad categories of the school's charter: Teaching, Spirituality, Community, and Justice. In accordance with Lietz, Langer and Furman (2006) the trustworthiness of the data was ensured through a process of triangulation by observer, peer debriefing and member checking. The first draft of the narrative was labelled the 'researcher story.' The team then worked together to develop a Powerpoint display that could be shared with the school leadership. This draft of the narrative contained summaries of de-identified data and provided an opportunity to member check prior to the development of the second narrative the "shared story.' A hard copy of the Powerpoint display was provided to the school leadership team for 
reflection and deliberation. Feedback from the school leadership team was then used to check the trustworthiness of what was stated in the 'researcher story' to develop the 'shared story'. The 'shared story' draft was considered trustworthy because it attended to research rigour through researcher reflexivity, triangulation of data sources and observers and member checking with the school site leadership team.

The revised 'shared story' was presented to the staff of the school in the form of a Powerpoint presentation. Hard copies of this draft of the narrative were also made available. Feedback was provided by staff in the form of responses to an anonymous questionnaire. This questionnaire asked staff to provide concrete examples of what the school does well, what the school can improve now, and what the school can improve in the future. These responses were collated and informed a final draft of the school narrative that was presented to the school and to its governing body for professional development purposes. This final phase added further opportunities for developing the rigour of this research evidenced by the audit trail established through the different versions of the story, researcher reflexivity, triangulation of data sources and member checking with the whole school staff. It must be noted that the school narratives were not checked with students or parents due to an expressed desire by schools to release the narratives to students and parents for comment as part of a system wide school renewal process. Such requests were deemed by the researchers to be acceptable in the light of the purpose of the research, namely, to inform the further development of the SRPT, and in terms of the maintenance of a productive trust relationship between researchers and users of the research.

The authoring of the school narrative involved three stages. The first focused on school administrators who assisted researchers to fill in the gaps in the story in relation to the culture of their school. Second, this revised story was shared with staff at professional development days for the purpose of 'member checking' the perceptions revealed in the 
narrative. This member checking involved each staff member being presented with the school narrative and then responding to this presentation by anonymously completing a feedback questionnaire. This questionnaire asked staff to provide concrete examples of what the school does well, what the school can improve now, and what the school can improve in the future. Thirdly, the responses from the staff feedback questionnaire were collated and informed a final draft of the school narrative that was presented to schools for professional development purposes. Each narrative presented aspects of the life and culture of the school under the headings of the sub-categories presented in Table 4. These stories were then interpreted through the lens provided by Sultman and Brown (2011) as outlined below.

\section{Development of the Profiling Tool}

Through conducting research on the identity dimensions of the Catholic school key organisational dimensions of the dynamic life of a Catholic school were identified (see also Sultmann and Brown, 2011). These were nominated as interdependent pillars and incorporated aspects of Faith, Learning, Leadership, Formation and Community. These pillars provide a lens through which to integrate data related to specific elements of identity, their connectivity as sub-systems, and their interdependence. The pillars also provided a framework in which to situate 'The Charter' of the faith based school system in which the research was conducted. The summary of perspectives gained from within and across strategic pillars invites the elaboration of a definitional perspective of identity that can be used to promote discussions about a school's vision and mission. To ensure that the research reported in this article was of use to schools beyond the Catholic system, Sultmann and Brown's (2011) pillars were extended through a consideration of a wide range of Australian and International documentation such as the Melbourne Declaration on Educational Goals for Young Australians (MCEECTYA, 2008) and The Salamanca Statement and Framework for Action on Special Needs Education (UNESCO, 1994). This process resulted in the 
development of the profiling tool organisational categories. Each of these categories was defined based on the literature, observation data, development of the stories for each of the sites, and national and international policy documents and literature. This process resulted in the initial Sultmann and Brown (2011) ideas being reconceptualised within this study. The main point of difference was the reconceptualisation of the notion of 'faith' from the Sultman and Brown work into the broader term 'culture.'

The term culture is defined in this research as symbolic and materially constituted social inheritance, embodied in language and social practices, of a social group (Cole, 2010). The Catholic School on the Threshold of the Third Millennium (Congregation for Catholic Education, 1998) highlights the significance of the relationship between faith and culture in the life of the Catholic school. According to this papal document, it is the Catholic school's mission, and by implication the task of school renewal, to support a mission that is prophetic, responsive to the signs of the times through dialogue, recognises the relationship between formation and experience, values the ministry of teachers and is faithful to the Tradition of integrating faith with life as culture is experienced. As such, it may be stated that faith within the context of the Catholic school is expressed through the culture of the school community, that is, the symbolic and materially constituted social inheritance of the community as embodied in language and social practice (Sultmann \& Brown, 2016). For this reason, the research team was comfortable with using the term 'culture', instead of 'faith' in the design of the SRPT. In considering the development of a tool that has the ability for application across different sectors of schooling, culture as a term allowed for each site to identify the approach to culture that is most appropriate for renewal to be considered. Table 2 provides a comparison of the pillars of Catholic school identity as defined by Sultmann and Brown (2011) and the categories of the SRPT as interpreted by the researchers. 


\section{\{INSERT TABLE 2 HERE $\}$}

As can be seen in Table 2, the revised categories provide a framework that can be used to provide insights into the cultural, social, organisational, and pedagogical dimensions of a school. These insights can be used by interested members of a school community to initiate and inform discussions about school renewal. To ensure that insights could be gathered in an informed, systematic and rigorous manner, the development of the SRPT went through a three phase process.

\section{Phase 1: Collating stories and translating perceptions into items to suit three audiences:}

\section{teachers, parents, students.}

In order to ensure that the development of the SRPT was consistent with national and international values frameworks, a whole day meeting was held with an international human rights advocate, education system administrators, school principals, teachers and the research team. The agenda for the meeting revolved around the following questions: What should the profiling tool do? What should it look like? and What must the profiling tool be? These questions were chosen because they reflect the theoretical framework upon which the research is based. Namely, the question "What should the profiling tool do?" has the potential to focus participants' attention on not only the needs of the collective system of education but also on the needs of the individual school. "What should it look like?" has the potential to focus attention on eliciting the participation of all members of the school community administrators, teachers, students, parents and youth workers. "What must the profiling tool do?" has the potential to focus attention on a 'learning-based' approach to school renewal. A synopsis of outcomes from the meeting is presented in Table 3.

\section{\{INSERT TABLE 3 HERE\}}

As can be seen from Table 3, the outcomes from the whole day meeting provided direction to the development of the SRPT and these directions are in the spirit of the 
Education Policy Outlook 2015: Making Reforms Happen, an international document that supports the view: “... that self-evaluation should actively involve and relate to the work of all school staff members" (OECD, 2015:131).

In order to ensure that the SRPT had potential to capture perceptions of difference between policy and practice and be relevant to the formation of all school community members, the school narratives were revisited. This revisiting required each narrative to be analysed in terms of the cultural characteristics displayed in each narrative text and in terms of the language used to express those characteristics. This analysis was conducted by three members of the research team and resulted in the findings summarised in Table 4.

\section{\{INSERT TABLE 4 HERE\}}

The summary of findings presented in Table 4, is representative of a school system made up of schools and educational entities that identify with a distinctive faith-based value framework. In the light of this framework, as signified by the system's charter of values, it was decided to incorporate the findings into the drafting process of the SRPT and that a separate version of the profiling tool would be developed for use in the alternative education schools. In order to ensure that the SRPT had the potential to engage multiple audiences with multiple levels of literacy, it was also decided that four versions of the SRPT would be developed for each school site - an administrator version, a teacher version, a student version and a parent version.

Once these decisions had been made, members of the research team revisited the school narratives, observational data, interview data and staff feedback data meeting regularly over a 3 month period to design survey items to populate the SRPT. Items were first written in the language of the researchers and then each item was tailored to meet the perceived needs of key stakeholders groups (administration, teachers, students and parents). 
Table 5 provides a break-up of the number of items, per profiling tool category that were developed.

\section{$\{$ INSERT TABLE 5 $\}$}

As can be seen in Table 5, three items gathered demographic information from the survey participants (Gender, Age, Year level [for students], Curriculum Area Taught, e.g., English, Mathematics, Number of Years Teaching/Working at the school [for staff]). The six items that explored the category Culture focused on philosophy, the differentiation of the curriculum, and communication, with one opportunity being provided for respondents to make their own comment in this category. This opportunity for comment was provided also in each of the other categories. The items exploring Teaching and Learning focused on pedagogy, lesson content, pastoral care, and the individual needs of students. Items exploring Community focused on inclusivity, service learning, resources and engagement, those exploring Leadership focused on values, participation, citizenship and behaviour management, with those exploring Formation focusing on mission, assessment, professional development and reflection. The five items relating to the category Final Questions explored issues related to celebration, social justice, the relevance of what was being taught to students' lives, and relationships. Table 6 provides a sample of survey items from each category as tailored to the perceived language needs of each stakeholder group.

\{INSERT TABLE 6$\}$

The sample of survey items presented in Table 6 represents the researchers' attempts to gain some sense of equivalence in meaning across the four groups of stakeholders. It is appreciated that respondents read questions in terms of their understanding of the world in which they live and the purpose of the interview situation (Braun \& Harkness, 2005). However, as determined from the all-day meeting, the purpose of the profiling tool was never 
to be an evaluation of a school or education system. Its purpose was to be a device for providing information that could be used to promote discussions about school renewal by key members of a school community (administrators, teachers, students, and parents). As such, a broad approach to meaning equivalence was afforded in the hope that each stakeholder group would use the open response opportunities to reveal a particular interpretation of an item or a category of items. What was important to the research team was that members of each stakeholder group would see the survey items as being relevant to their experience of the world and engage with the SRPT.

\section{Phase 2: Trialling the SRPT at a typical school within the system.}

Pilot study site selection/negotiating access

An appropriate case study site, a co-educational secondary college located in the centre of a metropolitan city, was selected on the basis of the school's involvement in earlier phases of profiling tool development and the willingness of the school community to engage in the process of data collection to assist in their school renewal efforts. Access to the site was negotiated with the principal, entailing discussions of an appropriate time and location to administer the surveys, and the planning of a communication strategy to inform relevant stakeholders. The surveys were made available in equivalent print and online versions. The surveys for the key stakeholder groups were again tailored, in collaboration with the school, in terms of the terminology used to ensure that the profiling items used language that was most familiar within this school's particular context.

\section{Tool administration}

The tool was made available to the key stakeholder groups (parents, teachers, administrators, and students in Years 8, 10 and 11) in the tenth month of the school year for a period of two weeks. In total, 14 parents, 17 teachers and administrators and 25 students completed on-line 
surveys. The mean age of students was 15.8 years $(\mathrm{SD}=1.2)$ and ages ranged from 13 to 17 years.

\section{Data analysis}

Data collected were subject to Principal Components Analysis (PCA) for the purpose of refining the survey. Factor analysis as outlined by Pallant (2007) was used to refine the SRPT which comprised six scales (categories) with items ranging in number from five to twelve. The scales were analysed using SPSS version 20. Due to the small number of participants and as the aim was to refine rather than statistically validate, PCA was used to determine the least number of factors that could account for the greatest amount of variance in the data. Kaiser's criterion (ensuring eigenvalues $>1$ ), Parallel analysis and scree tests were used to decide on the most appropriate number of factors for further analysis.

While there is controversy about the use of PCA to statistically confirm observations in the social sciences its use as a method of exploring a data set is fairly widely accepted (Osborne \& Costello, 2004; Osborne \& Costello, 2009). It is for this purpose that we employed PCA as an analytic tool. Researchers have used sample sizes of 50+ to sufficient effect (see the work of Barrett, \& Kline, 1981). Small sample sizes in the social sciences are common when researchers are confined by the parameters of their research, for example, the use of convenience sampling (Marshall, 1996). As in the case of the development of the SRPT, sample size was basically determined by the pilot school community in terms of individual school community member's willingness to participate and in terms of the school's effectiveness in promoting the research to the school community. It was for these reasons that the research team decided that a sample size of 56 was sufficient to progress the analysis of data using PCA to refine and explore the data set related to the SRPT. The aim was to refine through exploratory PCA rather than validate through confirmatory PCA. The researchers were interested in exploring the dominant patterns in the data set in order to refine the SRPT 
and to formulate issues to be addressed in further iterations of the SRPT (see Wold, Esbensen, \& Geladi, 1987). Once these issues have been dealt with, it is the intention of future research to move to the use of confirmatory factor analysis to see if the SRPT has the same structure across multiple school systems.

In addition to these methods, inspection of the component matrix for values greater than .4 and the pattern matrix for values greater than .3 were used to provide further evidence for the number of factors (Pallant, 2007). For scales with two or more identified factors the whole process was repeated but this time forcing the number of factors identified. Factor rotation using the Varimax method was then used to decide which items correlated most strongly with each factor and inspection of the communality values were used to decide upon items that could be eliminated. Table 7 shows the suitability of all scales to be subjected to PCA.

\section{$\{$ INSERT TABLE 7 $\}$}

Each scale was further subjected to two rounds of analysis. The first analysis was to determine the number of factors (used interchangeably with components) apparent in each scale. Individual items were assessed for their suitability of inclusion and a recommendation was made as to which items could be removed without adversely affecting the ability of the items to measure that scale. Table 8 presents a summary of the analysis.

\section{$\{$ INSERT TABLE 8$\}$}

As suggested in Table 8, factor analysis of the six scales (categories) of the profiling tool revealed culture, teaching and learning, leadership and formation as having two factors, and community and integration (final questions) as consisting of single factors. Examination of the commonalities identified the possible removal of two items (TL4, TL6) from Teaching and Learning and a single item (LE1) from Leadership. Examination of the results of an Oblimin rotation (Pallant, 2007) of the scales that consisted of two factors revealed which 
items correlated most strongly with the two factors identified. This analysis allowed the reduction in the number of items of the profiling tool whilst still maintaining its potential to measure the identified scale and also to reveal the underlying factors (subscales) within each scale. The next step in the process was to reformulate the SRPT in accordance with this analysis.

The reformulated SRPT incorporated a Likert type scale for each item with 4 points (strongly disagree, disagree, agree, strongly agree) and a fifth point (not applicable) that could be used by respondents when they felt that the item did not apply to the context of their role within the school. Figure 3 provides a sample of the SRPT for the Category - Culture, as presented to students. At the end of each SRPT category as represented in Figure 3, respondents were provided with the opportunity to record an open response to their experience of the category, for example, Culture, as perceived in their interactions with the school.

\section{\{INSERT FIGURE 3$\}$}

At the completion of the two week period that the profiling surveys were made available, participants' Likert type scale responses to each survey item were statistically analysed using SPSS version 20. This analysis revealed that there was little difference in the responses provided by teachers and administrators. As such the data from these two surveys were collapsed and a report generated. The report using the items from the teacher survey as a template was a compilation of the three surveys designed to gather key stakeholder (staff, parents and students) perceptions. The report stressed that the analysis generated was not intended to be an evaluative means by which schools would be rated in the formal sense but was provided to engage stakeholder groups in evidenced-based conversations and discussions about school renewal. 
The report consisted of four sections. Section 1 provided demographic information about the participants, numbers of teachers, students and parents who participated, the school year level for the students (Grade 8, etc.,), the disciplinary area of the teachers (Mathematics, English, etc.), and the gender and year level of the student/s that the parents were referring to. Section 2 presented the complied data as bar graphs for each of the items in each of the categories (see Figure 4 that shows the bar graph for the category Community).

\section{\{INSERT FIGURE 4 HERE\}}

As can be seen in Figure 4, the bar graph represents the average rating for all respondents for individual items. These were listed in descending order in each graph. This gives an overall sense of the school community's perception on each item. The ratings of moderate, high and very high give a sense of how the school community perceives the school to be performing on each item. It must be noted that the ratings of high, moderate and low are descriptive of participant agreement levels rather than evaluative terms. For example, the item 'This school has a well developed and planned program of service learning' simply provides an opportunity for participants to agree or disagree with the statement. Whether such a practice is valued by participants is something for teachers, students and parents to comment upon in an open response or to discuss in their conversations about school renewal. The letters represent the average rating for students $(\mathrm{S})$, parents $(\mathrm{P})$ and teachers $(\mathrm{T})$. This gives an overall sense of the perceptions of each stakeholder group. Items with a letter in brackets indicate where perceptions amongst the stakeholder groups (i.e., students, parents and teachers) differ significantly. For items without a letter, it could be said that stakeholder groups agree with each other on that item. At the bottom of each graph is an explanation of which groups differ significantly in a statistical sense.

Section 2 of the report provided the open ended responses of participants to the survey in a manner that clustered the responses under the Headings: Culture; Teaching and Learning; 
Community; Leadership; Formation; Final Questions. It was hoped that clustering the open responses in this manner would assist schools to frame their discussions about school renewal in the words of their teachers, students and parents.

\section{Descriptive analysis of phase 2 responses}

What follows is a descriptive analysis of participant (teacher, student, parent) responses to the survey items. The analysis is informed by participants' open responses. It should be noted, once again, that ratings of 'high', 'moderate', or 'low' refer to agreement levels not to evaluations of practices. The purpose of the analysis of the open responses was twofold. Firstly, to highlight issues that a school might include in conversations with community members about school renewal. For example, in terms of school culture the analysis highlighted that there may be a lack of awareness by students of the school's ability to plan and consistently communicate the school's philosophy, to families, to other schools and communities. Lack of awareness was also suggested as being an issue for students in the domain of teaching and learning in relation to 'pastoral care' and acknowledgement of 'cultural backgrounds'. As such it was hoped that the analysis would encourage school communities to incorporate issues, for example student awareness raising, in future conversations about school renewal. In so doing, it may be said that the analysis provides the school community with the impetus to give students permission to engage in conversations that go beyond the discussion of lunch breaks, discos and school trips to talk about issues that go to the very heart of school renewal and in so doing to treat students as agents of transformation (Fielding, 2001a). Secondly, the analysis of the 'open responses' from the pilot study sought to inform the further development of the SRPT before being delivered to a larger more representative sample of schools.

While the purpose of the analysis was descriptive, the analytic method addressed three issues of quality and credibility as referred to by Patton (1999). First, procedure for 
gathering the open response data was rigorous in that the responses were collected from participants anonymously via an on-line survey. Second the responses were analysed by two researchers who cross-referenced student, teacher and parent responses with school and classroom observations, school staff interviews collected during phase 1 of the study, and documentation (e.g., school newsletters) provided by the leadership of the school. Third, researchers engaged in ongoing conversations about particular open responses where there was disagreement about interpretation until agreement was reached. Fourth, initial analyses of open responses were presented to the school leadership, staff and system authority to check for reasonableness.

It must be noted that the analysis of open responses was not checked with students or parents due to an expressed desire by the school to release the analysis to students and parents for comment as part of a school renewal process. Such a request is not unusual for a school who is accustomed to having the locus of control for change nestled within its leadership structure (Cavanagh \& Waugh, 2004). Acceptance of such a request by researchers is acceptable in the light of the purpose of the research, namely, to inform the further development of the SRPT for the purpose of raising issues that the whole school community could engage with in conversations around school renewal, and in terms of a form of tactfulness necessary to ensuring the development of a productive trust relationship between researchers and users of the research (see Morgan \& Hunt, 1994). However, the researchers were a central part of the schools leadership presentation of the report to the school community that included parent and student representatives and feedback from this event along with feedback from a presentation made to the schools' governance board was used to inform the further development of the SRPT. 


\section{Culture}

Levels of agreement were rated high for two of the six items that referred to culture and rated moderate for the remaining four. There was general agreement between the key stakeholders for three of the six items. Students perceived the school's ability to plan and consistently communicate the school's philosophy, to families, to other schools and communities as lower than that of both parents and teachers. Inspection of open responses suggests that this may simply be due to a lack of awareness whereas parents and teachers were aware of communications, for example, via staff meetings and school newsletters. Student agreement levels were also lower for the item 'we go out of our way to celebrate staff, student and family achievement, diversity and spirituality'. Parents agreed more than students or teachers with the statement that the 'same curriculum and support is provided to all students so as to achieve the goals of the school'. Inspection of open responses suggests that parents are generally pleased with the level of support their children receive.

\section{Teaching and Learning}

Levels of agreement were rated high for five of the twelve items that referred to teaching and learning and rated moderate for the remaining seven. Teachers rated the statements 'I model the quality of student work required to achieve the standards', 'I develop lesson and unit plans on the basis of students' prior understanding of a topic' and 'I often use small group and whole group discussions to build students' knowledge of a topic' higher than both parents and students. Students agreed less with the statements 'pastoral care is integrated/embedded into all school activities' and 'different cultural backgrounds are acknowledged in school activities and the curriculum' than both parents and teachers who tended not to differ in their views on these two items. Inspection of open responses suggests that this may be an issue of awareness raising with the student body. 


\section{Community}

Agreement levels were rated high on one of the nine items that measured community and rated moderate for the remaining eight. Students rated 'Aboriginal and Torres Strait Islander culture is evident in curriculum, policy and practice at our school', 'the school makes best use of school and community resources for educational outcomes' lower than both parents and teachers. Students rated 'this school has a well developed and planned program of service learning' and 'service learning is part of the curriculum and students are taught how to engage in reflective practice' lower than parents. Open responses suggest that students have a low awareness of issues related to cultural awareness, resources, and service learning. Students rated 'the school plans programs that support the development of the school and community' lower than teachers while teachers rated 'the school carefully plans activities that are representative of a range of cultures' higher than both parents and students who did not differ in their views on this statement. The consistent theme of student perceptions being generally lower than parent and/or teacher perceptions was apparent in the open responses.

\section{Leadership}

Levels of agreement were rated high on five of the nine items that measured leadership and rated moderate for the remaining four. Student agreement levels on 'there are a range of support systems to ensure that any child who came to school without the necessities of school life would be catered for', 'behaviour management is based on student development and restoring relationships', 'a range of professional development activities focussed on student learning are available to staff' and 'behaviour management is based on students understanding a clear set of consequences for non-compliance' were lower than parental levels. 


\section{Formation}

Agreement levels were rated moderate for all ten items that referred to formation. Students rated 'the Pastoral care program of the school is designed to develop the students so they may reach their full potential as members of the community' lower than parents, and rated 'as a school we have set policy and structures that allow us to regularly reflect on our vision and mission' lower than teachers. Students also rated 'through regular planned activities we reflect on school relationships and the life and mission of the school' lower than both parents and teachers. Inspection of open responses suggests that students had minimal understanding of the school's mission and vision.

\section{Final questions}

Agreement levels rated high on one item out of the six items that referred to this section of the survey with the remaining five being rated moderate. Teachers rated 'at this school social justice issues are integrated throughout the school curriculum and explicitly focused upon in service learning programs' significantly higher than both parents and students. Open responses suggest that teachers were aware of the planning that has ensured that social justice is explicitly focused upon in service learning programs. Key stake holder levels of agreement did not differ on the remaining four items.

Following the survey report being sent to the school and with the school's permission, a presentation of the pilot study was made to the school community and to the board of governance of the system of education that housed the school. Feedback from the school community and from the members of the board was then incorporated into the final phase of the study. The analysis provided the school community with the impetus to voice issues that go to the very heart of school renewal and in so doing to treat students and parents as agents of transformation (Fielding, 2001b).

Phase 3: Implementing the SRPT at a representative sample of school sites. 
At the beginning of 2013, seven school sites accepted the invitation to engage with the School Renewal Profiling Tool (see Table 9). As presented in Table 9, the schools that elected to engage with the SRPT were reflective of the diversity of the national network of schools involved in the study and incorporated representation across Australian state boundaries, enrolment profile, size, location, and socio-economic status.

\section{\{INSERT TABLE 9 HERE $\}$}

Engaging with the SRPT required a member of the research team to make contact with the school by email and by phone to (a) provide information about the development, nature and purpose of the SRPT, (b) provide information about the nature of the report that will be issued to the school at the conclusion of the survey and related confidentiality issues, (c) author and format the information that would be provided to parents, teachers and students regarding the nature and requirements of the survey, (d) negotiate a two week window in which to make the survey available to parents, teachers and students, (e) format the language of survey items to the requirements of the school, for example, the use of the term school or college or centre or program, the use of the term students or boys or young people or pupils, the use of the term teachers or staff or professionals, et cetera, and to (f) determine whether paper copies of the survey were to be made available to parents, teachers and students. All schools except school 7 opted to provide parents, teachers and students with the online version of the survey only, whereas school seven opted to provide parents, teachers and students with the paper only version of the survey.

Towards the end of 2013, principals of the schools that had engaged with the profiling tool were provided with a feedback sheet (see Figure 5) which utilised the Plus/Minus/Interesting (PMI) format (de Bono, 2006). This format was chosen because it has been successfully used in the past to promote critical reflection and ownership within and by research participants (see, e.g., Bernero, 2000). 


\section{\{INSERT FIGURE HERE 5 $\}$}

The reflection sheet provided participants with an opportunity to provide a recommendation and an open response relating to the SRPT. Of the seven schools all but one stated that they would recommend that the profiling tool be used by other schools. The school that did not make such a recommendation stated that the survey documents that the school already had in place were sufficient for its school renewal processes. Feedback responses were sent to the system authority, only a summary of responses was provided to researchers. However, in terms of the SRPT summary, Pluses related to providing insights into how the school's learning environments, curriculum and service programs, philosophy and values, communal relationships, enrolment access, and culture were perceived by stakeholders. Minuses related to providing insights into issues related to collegiality between primary and secondary staff, curriculum differentiation, communication between staff and the leadership of the school/s, technology and resources, classroom pedagogy, class sizes, and transparency in decision making. Points of Interest related to providing insights into issues relating to Australian Profession Standards for Teachers and Curriculum, embedding the philosophy of the school into the lived culture of the school, multiculturalism, behavior management, academic and sporting excellence, social justice, student diversity, the nature of family, the overcrowded curriculum, and education pathways.

The Australian Professional Standards for Teachers (MCEECDYA, 2011) make explicit the elements of high-quality teaching expected of all teachers around the nation. The framework is comprised of seven standards grouped into the domains of: professional knowledge; professional practice and professional engagement. The standards are organised into four career stages and guide the preparation, support and development of all teachers. Standard 7 - engage professionally with colleagues, parents/carers and the community aligns particularly strongly with this study and hence it is unsurprising that insights reflecting 
the national teaching standards were evident. Australia also has in place a nationally developed curriculum that guides student learning from Foundation (Preparatory) to Year 10 (ACARA, 2016) so again, it is unsurprising that reference might be made to this curriculum. An indication of the usefulness of the SRPT is reflected in the fact that the System Authority has recommended to its schools that they use the SRPT to assist in their on-going processes of reflection and renewal. To this end, a further seven schools have engaged with the SRPT over the 2014/2015 academic years.

\section{Limitations of the study}

While the use of surveys is an established practice within the school renewal literature, the SRPT relies on self-reported perceptions of teachers, parents and students from a select group of independent Catholic schools. Even though the range of schools catered for broad populations of students in terms of socio-economic status (high, middle, low), location (urban, rural, regional), and ethnicity (indigenous, Asian, African, European) the self-report data that the SRPT collects may have biases about a particular school, region or ethnic group. While each of the schools ascribe to a common Charter of values that guide their Vision and Mission, the self-report data that the SRPT collects may also have biases that relate to providing the 'expected response' or to personal interpretations and/or prioritizations of 'Teaching', 'Spirituality', 'Community', and ‘Justice.

The 'power' in organizational structures is one of the major limitations that affects this study. Within any mainstream school there is an institutionalised, hierarchical arrangement of power relations (Fielding, 2001a). As such, there is a real risk that meaning making for peripheral community members, such as students, parents and teachers who, for various reasons, are not fully engaged in the life of the school community, may simply involve reflecting meaning as communicated by the dominant source of power, for example, the school principal (Roberts, 2006). Furthermore, the extent to which teachers, parents and 
students who respond to the SRPT have the same perceptions that teachers, parents and students who choose not to respond would have is not known. These particular limitations could be addressed in future research related to the design of the SRPT. However, present techniques employed in the reporting of the SRPT such as the aggregation of responses into 3 population groups for each school (teacher, parent, student) for each survey item, the anonymity of the respondents and the provision of one report to each school go some way to minimising some of these limitations.

\section{Discussion/Conclusion}

This article explores a learning based approach to school renewal through the development and trialling of the SRPT to support schools to self-reflect on school renewal. Informed by a sociocultural approach to learning, the SRPT was developed to provide school communities with an empirical view of learning as situated practice.

Findings from the testing and trialling of the tool revealed the breadth, depth and uniqueness of school identity. While change in the appreciation of school identity can be recognized at theory and practice levels, the question as to the nature of contemporary school communities remains a continuing challenge. Consequently, we agree with Bowen, Rose and Ware (2006) that it makes sense to provide schools with tools that assist them to change or consolidate existing initiatives or to identify the need for new initiatives. The SRPT does this by providing empirical data that may help school communities to look beyond student achievement on external measures to reflect on, also, the organisational categories within their schools (e.g., Culture, Learning, Leadership, Formation and Community). The use of the SRPT is, therefore, particularly relevant for use within school sites where providing empirical data about the organisational categories that organise schools may help multidisciplinary staff to engage with and renew the mission of the school, to plan future resourcing, and to fulfil the accountability requirements of system, state and national authorities. 
Data from the pilot phase of the SRPT suggest that the SRPT has the potential to counter typical constructions of teacher and student in ways that promote teacher and student voice, namely, the means through which we make our thoughts known, represent our experience, and involve ourselves in life's decisions (Cook-Sather, 2006). For example, in the SRPT category of Teaching and Learning the SRPT pilot school survey revealed that there were significant differences between teacher and student perceptions of the quality of classroom work expected, the incorporation of prior learning into lesson topics, the integration of pastoral care into school activities, the inclusion of different cultural backgrounds into the school curriculum, and the use of small group work and discussion in class lessons. These differences in perceptions relate to the core of the teaching and learning mission of the school, areas of the life of the school that remain largely 'forbidden areas of enquiry' for students (Fielding, 2001a:101).

By revealing areas of difference between teachers and students, the SRPT provides opportunities for the thoughts of students to be heard beyond the ears of the classroom teacher and for perceptions of teachers to be recognised by school governing authorities. This expansion of audience for both teacher and student personal perceptions is necessary for the construction of teacher/student relationships that are able to step-outside the institutional hierarchy of roles to construct and engage student and teacher roles necessary for genuine school renewal and transformation (Fielding, 2001).

The results of the testing and trialling of the SRPT generally support the conceptual framework that informed its development. A sociocultural approach to situated learning holds that communities change, grow and are renewed through interweaving 'scientific' or 'schooled' understandings (e.g., those relating to the planned curriculum) with people's everyday understandings and experiences (e.g., those relating to the enacted curriculum) (Renshaw \& Brown, 2007). This interpretation focuses the issue of 'identity' on the distance 
between the organizational categories that frame the school context and the everyday knowledge and experience of members of the school community. The institutional context of schools, where the interweaving of the 'everyday' and the 'scientific' typically occurs, provides powerful messages to students, teachers and parents about their respective roles in the school community. For instance, in many mainstream schools, the ideal student is often constructed as a receptive learner who follows teacher directions and completes assigned tasks to the teacher's satisfaction. The ideal teacher is constructed most often as a benign classroom expert who can transmit cultural concepts using efficient and effective methods. Ideal parents are sometimes constructed as hard working, busy people, who leave their children's education to the expertise of the school. To move beyond these perceived ideals for the purpose of developing or renewing can be difficult because schools need to develop new ways to conceptualize roles for students, parents and teachers within the learning community, roles that are engaged through an authenticity of practice based on experience and evidence. The SRPT assists this conceptualising by providing student, parent and teacher perspectives on the organisational structures of the schools that frame their learning communities, perspectives that may assist school communities to co-author a school narrative where collective structures and individual agency may meet through learning (Wenger, 1998). In this way, the SRPT provides data that may assist school communities to become communities of practice by consolidating individual, private perceptions into collective and public visions in a way that is safe for the participants and that encourages all stakeholders to collectively reflect on school renewal.

Through providing a tool that assists educators and practitioners to hear the realities of power relations that exist in a school community and that assists school communities to self-identify and develop their own solutions to challenges that limit their capacity to engage in meaningful school renewal, the SRPT points towards an alternative path to school renewal. 
This alternative path identifies personal participation in the development of a collective view of what the school community values, a collective view authored from empirical data derived not from standardised tests or external accountability measures but from the voices of parents, teachers and students. After engaging in a testing and trialling process that required researchers to independently observe and rate observations, that required school narratives to be 'member checked' at leadership and staff levels, that sought and acted upon advice from local, national and international advisers and that undertook quantitative analysis for the purpose of refining survey items, it may be stated that at this point in time, the reliability and validity of the SRPT appear promising. It may also be stated that, as a result of the collaborative efforts between researchers, school communities and a school system authority, a School Renewal Profiling Tool has been developed that attempts to integrate the different components of a school community in a coherent way, a challenge issued by the OECD to improve school renewal (OECD, 2015). Further refinements are planned that include the targeted modifying of the SRPT for the purpose of integrating data sets, such as those provided by the National Assessment Program - Literacy and Numeracy (NAPLAN) and the Smarter Schools National Partnership on Low Socio-economic Status School Communities introduced by the Australian Government in 2008 and 2009 respectively, that are made collective and public by external bodies.

The practical implications of the development of the SRPT for school renewal are substantial. Although the place of values in school renewal has gained currency over the last decade, there is limited research available about the approaches taken by schools to incorporate values into their school renewal processes. Halstead and Taylor (2000) argue that a communal approach to incorporating values can be an effective means of bringing about school renewal. The development of a values approach to school renewal, as experienced in the SRPT, provides schools with a communal approach to school renewal that reflects on 
values as lived in school contexts. Armed with an effective tool to assist parents, students and teachers to reflect on values as lived in school contexts, educators will be better able to conduct research on how best to involve values, as reflected in school vision and mission statements, in a process of renewal of school organisational structures for the purpose of fostering school contexts that promote community building, that guide improvements in student learning and that promote increased satisfaction by important stakeholder groups. Moreover, given the efficacy of the SRPT to provide perspectives from parents, students and teachers, researchers will be able to obtain insights into the specific organisational categories where a school may need to focus its renewal efforts.

The research surrounding the development of the SRPT contributes to the field in two distinct ways. First, the development of the SRPT is based on a participatory approach to school renewal that identifies tools that bridge the personal and the collective (see Harré (1984). In so doing, it offers an approach to school renewal that focuses 'community of practice' (see Lave \& Wenger, 1991) dimensions of the personal and the collective such as 'doing', 'experience', 'identity' and 'belonging' on the values upon which the school community is based. The findings, therefore, have potential to assist a wider field of educators and practitioners to gain insights into issues that Fielding (2004) holds as being core to school transformation and renewal. For example, through offering parents, teachers and students an opportunity to record both in terms of a scale and through an open response format their personal perceptions of the life of the school community as they relate to issues such Teaching and Learning, Community, Leadership, and Formation, the SRPT has the potential to reveal to educators and practitioners the realities of power relations that exist in a school community. Such revelations may then be interpreted in the light of the school mission and vision and lead, eventually, to more open and equitable forms of dialogue 
between parents, teachers and students, an endeavour worth pursuing in terms of school renewal and transformation (Fielding, 2004).

Second, the fact that data from the SRPT is presented to school communities in a deidentified form the SRPT avoids the difficulty of what Fielding (2004) refers to as 'speaking about and for others' where the original thoughts of respondents are couched in the language and values of the researcher. The SRPT, then, becomes a tool for school communities to selfidentify and develop their own solutions to challenges that limit their capacity to engage in meaningful school renewal, a goal of school renewal advocated by organisations such as the OECD (see Education Policy Outlook: Making Reforms Happen, OECD, 2015). In so doing, the SRPT provides educators with insights into the dialogic relations of school communities that fall outside institutional tradition and habit.

The challenges faced in researching the development of the SRPT and its trial use revolved around issues related to the development of a trust relationship between researchers and the users of the research and the development of a working relationship between researchers and the participants in the research. Encountering and facing these challenges required constant negotiation and change and that diverse and innovative methodological structures were harnessed to ensure that the power relationships between researchers, system authorities and participants were more equitable, reliable and fruitful.

When developing a trust relationship with the users of the research, the researchers were aware that the locus of control for change within the system of independent schools being researched rested within the leadership structure of each school, a typical characteristic of conventional schooling (Fielding, 2001b). For example, the request by the pilot school to release the analysis of the trial of the SRPT to students and parents for comment as part of a school renewal process entailed that, in order to maintain the integrity of the analysis, the researchers took a central role in the school leadership's presentation of the analysis to the 
school community. The desire of some schools that their students not be audio or video recorded required the researchers to develop an Observational Schedule that placed students at the centre of the thinking about school practice. This was achieved by basing observation categories and descriptors on student focused models of philosophy such as the 'The Charter' and the Melbourne Declaration on Educational Goals for Young Australians (MCEETYA, 2008).

The development of a working relationship between researchers and the participants in the research required that researchers be constantly aware that they were guests within the school community, a legitimate identity for researchers to negotiate with others when working in a community to which they do not belong (Norton \& Early, 2011). For example, time management of the research nested mainly within the conventional school timetable. This required researchers to make observations of students and teachers in their regular timetabled classes, necessitating their being within a school for a number of days. Informing staff about the research required researchers to attend and participate in school staff meetings and professional development days. Nesting the research within a particular faith tradition even though some participants in the research did not ascribe to that tradition required researchers to couch the research within documentation such as The Salamanca Statement and Framework for Action on Special Needs Education (UNESCO, 1994) and to take advice from an international human rights advocate.

Despite the advantages, school renewal is a complex process that attempts to cover diverse stakeholder groups in diverse value contexts. At the outset we pointed to the current focus on system and school renewal (Mourshed, Chijioke\& Barber, 2010; OECD, 2015) as a means of improving student outcomes. It was noted that a focus on students and learning, building teachers' capacity, and engaging all stakeholders were features of successful reform. It is our contention that the SRPT is one model that genuinely incorporates each of these 
dimensions, hence it is worthy of further development and consideration. The research, to date, has mainly favoured quantitative approaches. The diversity that underlies the nature of school renewal would suggest that much could be gained by using a qualitative approach that provides empirical data such as that provided by the SRPT. Having said that, the process of a values approach to school renewal would benefit from further research that explored different ways of 'becoming an educator' in a school community. Such research would examine the roles of parents, students and teachers in school communities and focus on what it means for parents, students and teachers to become educators in a learning community.

\section{References}

Australian Curriculum and Reporting Authority (ACARA) (2016). Australian Curriculum Retrieved 4 April 2015 from http://www.australiancurriculum.edu.au/

Australian Government. (2005). National Framework for Values Education in Australian Schools. Retrieved 10.4.06. from

http://valueseducation.edu.au/verve/_resources/Framework_PDF_version_for_the web.pdf

Barrett, P. T., \& Kline, P. (1981). The observation to variable ratio in factor analysis. Personality Study and Group Behavior, 1, 23-33.

Bernero, J. (2000). Motivating students in math using cooperative learning. Retrieved 29.4.2015, from http://files.eric.ed.gov/fulltext/ED446999.pdf

Bowen, G. L., Rose, R. A., \& Ware, W. B. (2006). The reliability and validity of the School Success Profile Learning Organization measure. Evaluation and Program Planning, 29(1), 97-104. 
Braun, M., \& Harkness, J. A. (2005). Text and context: Challenges to comparability in survey questions. Methodological Aspects in Cross-national Research, 95-107.

Brown, J. S., \& Duguid, P. (1991). Organizational learning and communities-of-practice: Toward a unified view of working, learning, and innovation. Organization Science, 2(1), 4057.

Cavanagh, R. F., \& Waugh, R. F. (2004). Secondary school renewal: The effect of classroom learning culture on educational outcomes. Learning Environments Research, 7(3), 245-269. doi:10.1007/s10984-004-3296-5

Clifford, M., Menon, R., Gangi, T., Condon, C., \& Hornung, K. (2012). Measuring School Climate for Gauging Principal Performance: A Review of the Validity and Reliability of Publicly Accessible Measures. A Quality School Leadership Issue Brief. American Institutes for Research.

Cole, M. (2010). What's culture got to do with it? Educational research as a necessarily interdisciplinary enterprise. Educational Researcher, 39(6), 461-470.

Comber, B., \& Nixon, H. (2009). Teachers' work and pedagogy in an era of accountability. Discourse: studies in the cultural politics of education, 30(3), 333-345.

Congregation for Catholic Education. (1998). The Catholic School on the Threshold of the Third Millennium. Homebush: St Paul Publications. 
Cook-Sather, A. (2006) Sound, Presence, and Power: 'Student Voice' in Educational Research and Reform. Curriculum Inquiry, 36, 359-390.

De Bono, E. (2006). De Bono's thinking course. New York: Pearson Education.

Del Rio, P., \& Alvarez, A. (2007). Inside and outside the Zone of Proximal Development: An ecofunctional reading of Vygostky. In H. Daniels, M. Cole \& J. V. Wertsch (Eds.), The Cambridge companion to Vygotsky (pp. 276-306). New York: Cambridge University Press.

Fielding, M. (2001a). Beyond the rhetoric of student voice: New departures or new constraints in the transformation of 21st century schooling? Forum for Promoting 3-19 Comprehensive Education, 43(2), 100-109.

Fielding, M. (2001b). Students as radical agents of change. Journal of Educational Change, 2(2), 123-141.

Fielding, M. (2004). 'Transformative approaches to student voice: theoretical underpinnings, recalcitrant realities', British Educational Research Journal, 30(2), 295-311.

Gallucci, C. (2008). Districtwide instructional reform: Using sociocultural theory to link professional learning to organizational support. American Journal of Education, 114(4), 541581. 
Goos, M., Galbraith, P., \& Renshaw, P. (2002). Socially mediated metacognition: Creating collaborative zones of proximal development in small group problem solving. Educational Studies in Mathematics, 49(2), 193-223.

Gutiérrez, K. D., \& Stone, L. (2002). Hypermediating Literacy Activity: How Learning Contexts Gets Reorganized. In O. N. Saracho \& B. Spodek (Eds.), Contemporary Perspectives in Literacy in Early Childhood Education (Vol. 2, pp. 25-51). Greenwich, Connecticut: IAP Publishing.

Halstead, J. M., \& Taylor, M. J. (2000). Learning and teaching about values: A review of recent research. Cambridge Journal of Education, 30(2), 169-202.

Harland, T. (2003). Vygotsky's zone of proximal development and problem-based learning: Linking a theoretical concept with practice through action research. Teaching in Higher Education, 8(2), 263-272. doi: 10.1080/1356251032000052483

Harré, R. (1984). Personal being: A theory for individual psychology. Cambridge, MA: Harvard University Press.

Hildebrandt, M. (2008). Defining profiling: A new type of knowledge? Profiling the European Citizen: Cross-Disciplinary Perspectives (pp. 17-45).

Lave, J., \& Wenger, E. (1991). Situated learning: Legitimate peripheral participation. Cambridge, UK: Cambridge University Press. 
Lezotte, L. W., Hathaway, D. V., Miler, S. K., Passalacqua, J., \& Brookover, W. B. (1980). School learning climate and student achievement. Tallahassee, FL: SSTA Center, 53.

Lietz, C. A., Langer, C. L., \& Furman, R. (2006). Establishing trustworthiness in qualitative research in social work implications from a study regarding spirituality. Qualitative Social Work, 5(4), 441-458.

Lingard, R. L., Ladwig, J., Mills, M. D., Hayes, D., Luke, A., Gore, J., \& Christie, P. H. (2001). The Queensland school reform longitudinal study: A strategy for shared curriculum leadership. Teachers' manual.

Marshall, M. N. (1996). Sampling for qualitative research. Family Practice, 13(6), 522-526.

Ministerial Council for Education, Early Childhood Development and Youth Affairs (MCEECDYA). (2011). Australian Professional Standards for Teachers, Melbourne: AITSL.

Ministerial Council on Education, Employment, Training and Youth Affairs (MCEETYA). (2008). Melbourne Declaration on Educational Goals for Young Australians. Melbourne: Commonwealth of Australia.

Morgan, R. M., \& Hunt, S. D. (1994). The commitment-trust theory of relationship marketing. The Journal of Marketing, 20-38. doi: 10.2307/1252308 
Mourshed, M., Chijioke, C. \& Barber, M. (2010). How the world's most improved school systems keep getting better. McKinsey \& Company.

Norton, B., \& Early, M. (2011). Researcher identity, narrative inquiry, and language teaching research. Tesol Quarterly, 45(3), 415-439.

Noddings, N. (2003). Happiness and Education. New York: Cambridge University Press.

Organisation for Economic Co-operation and Development (OECD). (2015), Education Policy Outlook 2015: Making Reforms Happen, OECD Publishing. doi:10.1787/9789264225442-en

Osborne, J. W., \& Costello, A. B. (2004). Sample size and subject to item ratio in principal components analysis. Practical Assessment, Research \& Evaluation, 9(11), 8.

Osborne, J. W., \& Costello, A.B., (2009). Best practices in exploratory factor analysis: four recommendatios for getting the most from your analysis. Pan-Pacific Management Review, $12,(2), 131-146$.

Pallant, J. (2007). SPSS survival manual: A step-by-step guide to data analysis using SPSS version 15. Maidenhead, Berkshire, England: McGraw-Hill Education.

Peck, C. A., Gallucci, C., Sloan, T., \& Lippincott, A. (2009). Organizational learning and program renewal in teacher education: A socio-cultural theory of learning, innovation and change. Educational Research Review, 4(1), 16-25. 
Renshaw, P., \& Brown (2007). Formats of classroom talk for integrating everyday and scientific discourse: Replacement, interweaving, contextual privileging and pastiche. Language and Education, 21(6), 531-549.

Roberts, J. (2006). Limits to communities of practice. Journal of Management Studies, 43(3), 623-639.

Sultmann, W., \& Brown (2011). Modelling pillars of Catholic school identity: an Australian study. International Studies in Catholic Education, 3(1), 73-90.

Sultmann, W \& Brown (2016) Leadership and identity in the Catholic school: an Australian perspective, International Studies in Catholic Education, 8:1, 73-89.

Syed, M., \& Nelson, S. C. (2015). Guidelines for Establishing Reliability When Coding Narrative Data. Emerging Adulthood, 3(6), 375-387. doi:10.1177/2167696815587648

UNESCO. (1994). The Salamanca Statement and Framework for action on special needs education: adopted by the World Conference on Special Needs Education; Access and Quality. Salamanca, Spain, 7-10 June 1994. UNESCO.

Villegas, A. M., \& Lucas, T. (2002). Preparing culturally responsive teachers rethinking the curriculum. Journal of Teacher Education, 53(1), 20-32. 
Vygotsky, L. S. (1987). Thinking and speech. In R. W. Rieber \& A. S. Carton (Eds.), The collected works of L. S. Vygotsky: Problems of general psychology (Vol. 1). New York: Plenum.

Wenger, E. (1998). Communities of practice: learning, meaning, and identity. New York: Cambridge University Press.

Wertsch, J. V., \& Rupert, L. J. (1993). The authority of cultural tools in a sociocultural approach to mediated agency. Cognition and Instruction, 11(3-4), 227-239.

Wold, S., Esbensen, K., \& Geladi, P. (1987). Principal component analysis. Chemometrics and Intelligent Laboratory Systems, 2(1-3), 37-52. 
Table 1: Categories, sub-categories and sample descriptors developed for observational schedule.

\begin{tabular}{|c|c|c|}
\hline $\begin{array}{l}\text { Observation } \\
\text { Categories }\end{array}$ & $\begin{array}{l}\text { Observation Sub- } \\
\text { categories }\end{array}$ & Sample Descriptor for each sub-category \\
\hline Teaching & Holistic Education & $\begin{array}{l}\text { Integrated development occurs through quality teaching and learning. } \\
\text { Provides a curriculum attentive to the needs of each person (attentive } \\
\text { to individual needs). }\end{array}$ \\
\hline \multirow[t]{4}{*}{ Spirituality } & Spirituality & $\begin{array}{l}\text { Each person's story is unique and sacred. } \\
\text { - Nurtures and encourages the spirituality of each person. (individual } \\
\text { spirituality) }\end{array}$ \\
\hline & Faith in Action & $\begin{array}{l}\text { Each person is called to respond out of a personal relationship with God. } \\
\text { - Fostering a personal relationship with God through Jesus Christ. } \\
\text { (emphasis on the personal relationship with God) }\end{array}$ \\
\hline & Pastoral Care & $\begin{array}{l}\text { The dignity of each person as a child of God is at the heart of pastoral } \\
\text { care. } \\
\text { - Acknowledges the dignity of all its members, each formed in the } \\
\text { image of God. (Dignity) }\end{array}$ \\
\hline & $\begin{array}{l}\text { Reflective } \\
\text { Practice }\end{array}$ & $\begin{array}{l}\text { Reflective practice leads to personal and communal growth. } \\
\text { Actively encourages all its members - teachers, staff and students - to } \\
\text { reflect on the contemporary world in the light of the Gospel. } \\
\text { (reflection on contemporary world issues) }\end{array}$ \\
\hline \multirow[t]{3}{*}{ Community } & Community & $\begin{array}{l}\text { Each person is called to respond to community. } \\
\text { - Quality of personal relationships. (Relational Community) }\end{array}$ \\
\hline & Compassion & $\begin{array}{l}\text { Compassion is central to the life and teaching of Jesus. } \\
\text { Fosters in its members the mind and heart of our founder, who acted } \\
\text { with compassion. (fosters compassion) }\end{array}$ \\
\hline & At the margins & $\begin{array}{l}\text { Seeks out the marginalised. } \\
\text { - Stands in solidarity with those who are powerless and marginalised. } \\
\text { (recognition and support for the marginalised) }\end{array}$ \\
\hline Justice & Being just & Justice is integral to the vision of the Kingdom. \\
\hline
\end{tabular}


- Acts justly. This is reflected consistently in structures and processes. (Acting justly)

Service of others Service of others is integral to being a follower of Jesus.

- $\quad$ Promotes service of others, by way of significant learning experiences, as basic to fulfilling a Christian life. (promotes service to others)

Stewardship God's gifts are to be shared justly and used wisely.

- Acknowledges the traditional relationship of indigenous peoples with the land. (acknowledges historical foundations) 
Table 2: Comparison of Sultmann and Brown (2011) categories with those developed for the SRPT.

Sultmann and Brown (2011)

Faith - Faith tradition which shapes and nurtures the interdependent pillars of the Catholic school

Learning - Learning which is holistic through the integration of faith, life and culture

Community - Community facilitation and sharing of the movement of the Spirit through people, relationships, rituals and structures.

Leadership - Leadership as Christian praxis centred in service and communion and encompassing relevant competencies.

Formation - Formation through engagement with 'story' encompassing 'head', 'heart' and 'hand'

\section{SRPT Categories}

Culture - The thoughts and behaviours of its members; its attitudes, values, beliefs and world views; how members communicate this to one another and the outside world; how the community operates on a daily, term and yearly basis to fulfil its purpose and celebrate its successes.

Teaching and Learning - The teaching and learning that occurs in this community is holistic through the integration of life and culture. There is an emphasis on teacher-learner relationships and on the tools of curriculum, pedagogy and assessment that develop authentic, dynamic and creative learning communities. Explores formal and informal curriculum, pedagogy and assessment.

Community - The community is expressed through the culture and learning that develops personal competencies within social frameworks that foreground the needs of the collective.

Leadership - Leadership is evidenced within the relationships, rituals and structures of the community for the purpose of the ongoing development of an inclusive learning culture centred on justice, stewardship and service to others.

Formation - a process where the community collectively engages with their story of culture and 
processes in support of progressive transformation in Christ

Integration - Integration processes which align,

empower and engage a Spirit of meaning, service and presence. learning for the purposes of restoration and

transformation.

Integration (Final Questions) - the process that aligns or engages leadership or formation with culture, learning and community for the purpose of enacting the culture and learning of the community. 
Table 3: Synopsis of outcomes from whole day meeting

\begin{tabular}{|c|c|}
\hline Question & Outcome \\
\hline What should the profiling tool do? & $\begin{array}{l}\text { - } \text { Engage all members of the school community } \\
\text { - } \quad \text { Present a sociocultural view of learning } \\
\text { - } \text { Produce a productive view of each school site } \\
\text { - } \quad \text { Provide feedback on the cultural characteristics of a school } \\
\text { - } \quad \text { Feed into formation of all members of the school community }\end{array}$ \\
\hline What should it look like? & $\begin{array}{l}\text { - } \quad \text { Items to be grouped around categories } \\
\text { - Use Likert type scales } \\
\text { - } \quad \text { Provide space for open ended responses } \\
\text { - Able to be completed in a timely fashion } \\
\text { A school community rather than system document }\end{array}$ \\
\hline What must it be? & $\begin{array}{l}\text { - } \\
\text { - For multiple audiences from different schooling systems } \\
\text { - For a diverse range of people displaying diverse levels of literacy } \\
\text { - Formative } \\
\text { - } \quad \text { Easy to access }\end{array}$ \\
\hline
\end{tabular}


Table 4: Summary of findings of analysis of school narratives

\begin{tabular}{|c|c|}
\hline Type of School & Summary Finding \\
\hline Co-educational & - The term student to be replaced with 'young person' \\
\hline Alternative Education & $\begin{array}{l}\text { - The term teacher to be replaced with 'worker' } \\
\text { - The term parent to be replaced with 'carer' } \\
\text { - The Sultmann and Brown (2011) category 'integration' be deleted } \\
\text { - That gender neutral language be used }\end{array}$ \\
\hline Co-educational & - That the terms teacher, student and parent be retained \\
\hline Mainstream & $\begin{array}{l}\text { - That the term profiling tool be replaced with 'survey' } \\
\text { - That the term 'integration' be replaced with 'final questions' } \\
\text { - That gender neutral language be used }\end{array}$ \\
\hline Same sex Mainstream & $\begin{array}{l}\text { - That the terms teacher, student and parent be retained } \\
\text { - That the term 'improve' be replaced with 'continue to develop' } \\
\text { - That the term 'improve teaching and learning' be replaced with 'inform } \\
\text { teaching and learning' }\end{array}$ \\
\hline
\end{tabular}


Table 5: Break-up of the number of the SRPT survey items

\begin{tabular}{lll}
\hline Category & Number of Items & Open Written Response
\end{tabular}

Demographic Information 3

Culture

6

1 opportunity provided

Teaching and Learning

12

1 opportunity provided

Community

9

1 opportunity provided

Leadership

9

1 opportunity provided

Formation

10

1 opportunity provided

Final Questions

5

1 opportunity provided

Total

54

6 
Table 6: Sample of survey items, from each category, as tailored to the perceived language needs of stakeholder groups.

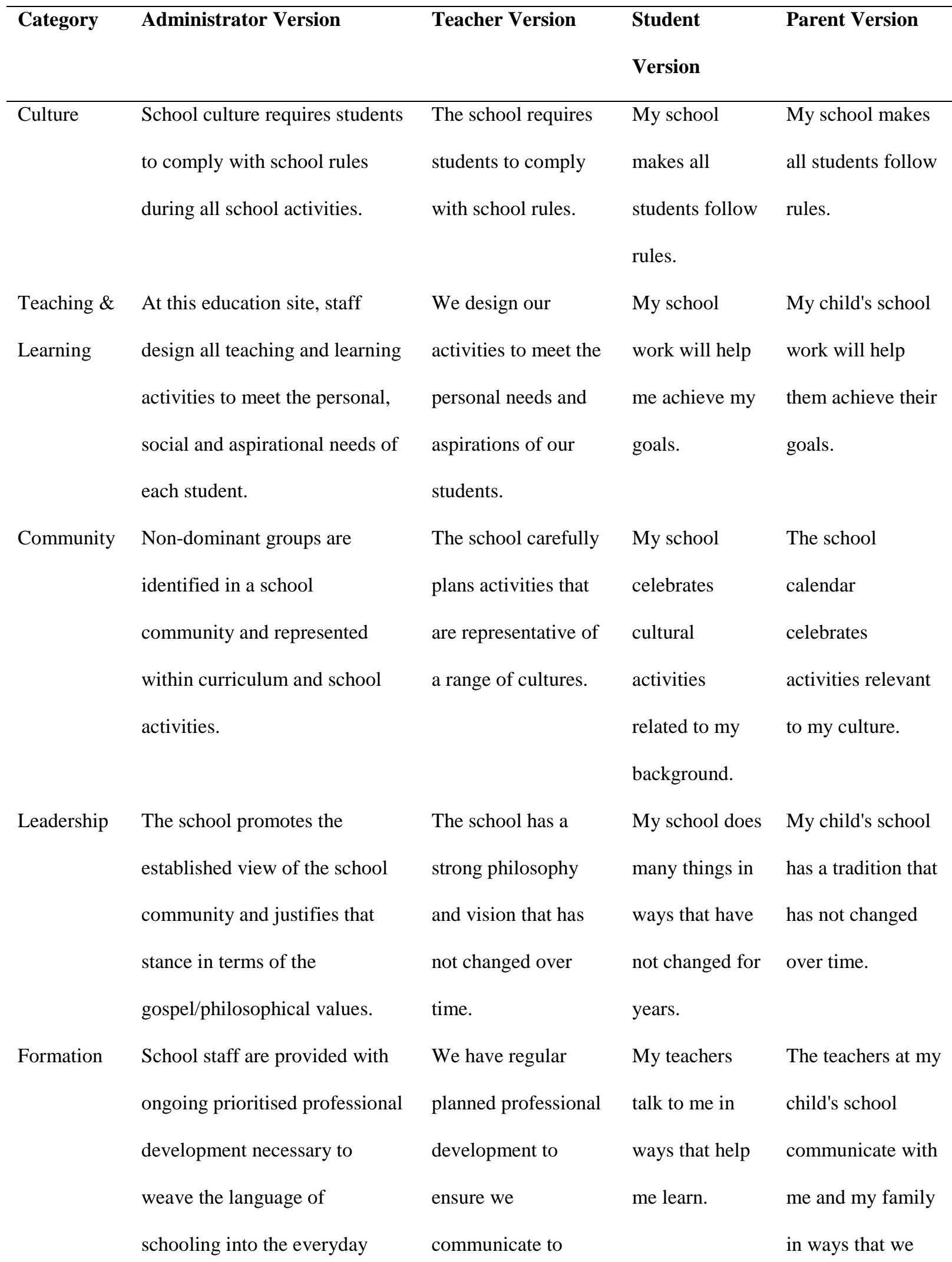




\begin{tabular}{|c|c|c|c|c|}
\hline & language of the student and their & students and families & & can understand \\
\hline & families in order to promote & in everyday language & & and find \\
\hline & equity in learning and the & in support of equity & & supportive. \\
\hline & development of student & and student & & \\
\hline & potential. & development. & & \\
\hline Final & Social justice issues are & At this school social & At school I & My child learns \\
\hline Questions & identified across the curriculum. & justice issues are & learn about & about social issues \\
\hline & Action taken to address social & integrated throughout & problems in the & at school and can \\
\hline & justice issues is integrated & the school curriculum & community and & participate in \\
\hline & across the curriculum with & and explicitly & I have the & community \\
\hline & service learning programs. & focused upon in & opportunity to & service programs. \\
\hline & & service learning & help. & \\
\hline & & programs. & & \\
\hline
\end{tabular}


Table 7: Suitability of scales subjected to PCA

\begin{tabular}{|c|c|c|c|}
\hline Scale (Category) & $\begin{array}{l}\text { KMO measure of } \\
\text { sampling adequacy }\end{array}$ & $\begin{array}{c}\text { Bartlett's test of } \\
\text { sphericity }\end{array}$ & Correlations above 0.3 \\
\hline Culture & .722 & $<.001$ & $\checkmark$ \\
\hline Teaching \& Learning & .629 & $<.001$ & $\checkmark$ \\
\hline Community & .739 & $<.001$ & $\checkmark$ \\
\hline Leadership & .767 & $<.001$ & $\checkmark$ \\
\hline Formation & .829 & $<.001$ & $\checkmark$ \\
\hline Final Questions & .710 & $<.001$ & $\checkmark$ \\
\hline
\end{tabular}


Table 8: Summary of factor analysis

\begin{tabular}{|c|c|c|c|c|c|}
\hline \multirow[t]{2}{*}{ Scale (Category) } & \multicolumn{2}{|c|}{ Number of items } & \multirow{2}{*}{$\begin{array}{c}\text { Item(s) } \\
\text { excluded }\end{array}$} & \multirow{2}{*}{$\begin{array}{c}\text { Number of } \\
\text { factors }\end{array}$} & \multirow{2}{*}{$\begin{array}{l}\text { Total variance } \\
\text { explained }\end{array}$} \\
\hline & Initial & final & & & \\
\hline Culture & 6 & 6 & - & 2 & $62.8 \%$ \\
\hline Teaching and & 12 & 10 & TL4, TL6 & 2 & $48.2 \%$ \\
\hline \multicolumn{6}{|l|}{ Learning } \\
\hline Community & 9 & 9 & - & 1 & $55.8 \%$ \\
\hline Leadership & 9 & 8 & LE1 & 2 & $64.7 \%$ \\
\hline Formation & 10 & 10 & - & 2 & $67.0 \%$ \\
\hline Final Questions & 5 & 5 & - & 1 & $55.5 \%$ \\
\hline
\end{tabular}


Table 9: School sites characteristics that have engaged with the profiling tool

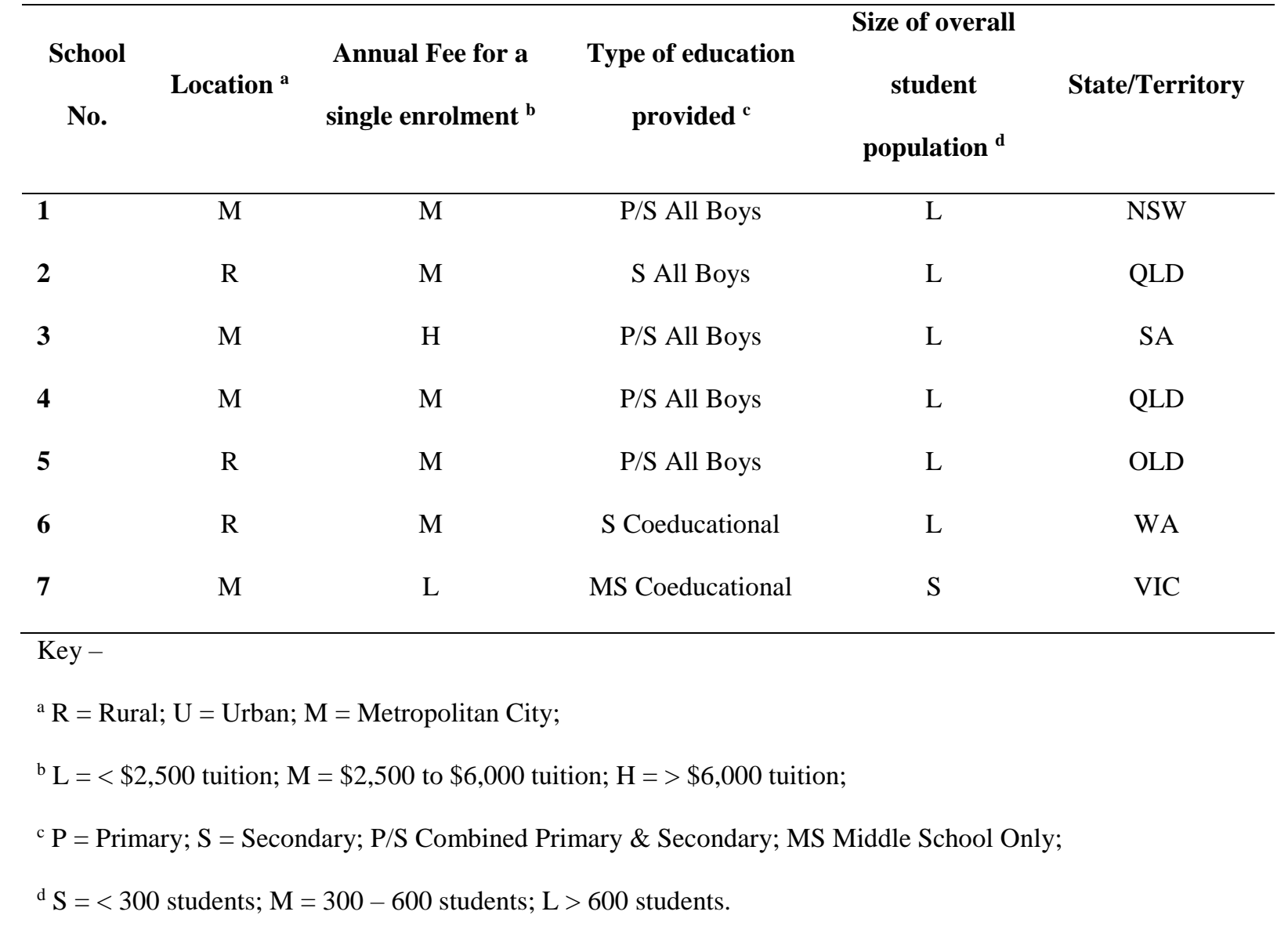




\begin{tabular}{|c|c|c|}
\hline \multicolumn{3}{|c|}{ Degree of Holistic Education Observed in a School } \\
\hline $\begin{array}{l}\text { Focus totally on individual } \\
\text { student results }\end{array}$ & 1 & $\begin{array}{l}\text { No evidence of holistic education within the classroom; no positive } \\
\text { recognition of difference and group identities; and no support for the } \\
\text { development of difference and group identities. Students are all treated } \\
\text { as individuals among a homogeneous group of learners (within the } \\
\text { expectations of the school). }\end{array}$ \\
\hline $\begin{array}{l}\text { Focus is on fixing students and } \\
\text { making them fit with the } \\
\text { expectations of the school }\end{array}$ & 2 & $\begin{array}{l}\text { Limited evidence of holistic education exists within the classroom; no } \\
\text { positive recognition of difference and group identities; and no support } \\
\text { for the development of difference and group identities. Students are all } \\
\text { treated as a homogenous group with student difference identified for } \\
\text { students to self correct. }\end{array}$ \\
\hline $\begin{array}{l}\text { Focus is on student difference } \\
\text { and making those differences fit } \\
\text { the expectations of the school }\end{array}$ & 3 & $\begin{array}{l}\text { Some evidence of holistic education exists within the classroom; some } \\
\text { recognition of difference and group identities; and limited support for } \\
\text { the development of difference and group identities to meet school } \\
\text { expectations. Student differences are recognised as needing to be } \\
\text { changed to meet school expectations with limited staff support. }\end{array}$ \\
\hline $\begin{array}{l}\text { Focus is on student difference } \\
\text { and taking those differences into } \\
\text { account when implementing the } \\
\text { expectations of the school }\end{array}$ & 4 & $\begin{array}{l}\text { There is a strong sense of holistic education within the classroom; } \\
\text { positive recognition of difference and group identities; and limited } \\
\text { support for the development of difference and group identities. Student } \\
\text { differences are recognised and occasionally taken into account using a } \\
\text { limited range of pedagogical approaches. }\end{array}$ \\
\hline $\begin{array}{l}\text { Focus is on student difference } \\
\text { and taking those differences into } \\
\text { account when designing the } \\
\text { expectations of the school }\end{array}$ & 5 & $\begin{array}{l}\text { There is a strong sense of holistic education within the classroom; } \\
\text { positive recognition of difference and group identities; and a supportive } \\
\text { environment for the production of difference and group identities. } \\
\text { Student differences are recognised and always taken into account in } \\
\text { multiple ways using a wide range of pedagogical approaches. }\end{array}$ \\
\hline
\end{tabular}

Figure 1: Observational sheet used for the sub-category 'community' 


\begin{tabular}{|c|c|}
\hline Category & Sample questions \\
\hline Teaching & $\begin{array}{l}\text { - How does teaching and learning relate to what you do at this school? } \\
\text { - Can you explain how you work with students in terms of teaching and learning? }\end{array}$ \\
\hline Spirituality & $\begin{array}{l}\text { - How does caring relate to what you do with young people at this school? } \\
\text { - Can you tell me something that explains how this works at this school? }\end{array}$ \\
\hline Community & $\begin{array}{l}\text { - How are people's lives valued at this school? } \\
\text { - Can you tell me how this valuing works at this school? }\end{array}$ \\
\hline Justice & $\begin{array}{l}\text { - How are issues of difference and diversity addressed at this school? } \\
\text { - Can you tell me something that explains how issues that cause tensions are dealt with at this } \\
\text { school? }\end{array}$ \\
\hline
\end{tabular}

Figure 2: Sample of interview questions for staff at school sites 


\section{CULTURE}

\begin{tabular}{|c|c|c|c|c|c|}
\hline $\begin{array}{l}\text { Please indicate the extent to which you agree or } \\
\text { disagree with each of the statements below. }\end{array}$ & $\begin{array}{l}\text { Strongly } \\
\text { Disagree }\end{array}$ & Disagree & Agree & $\begin{array}{l}\text { Strongly } \\
\text { Agree }\end{array}$ & $\begin{array}{c}\text { Not } \\
\text { Applicable }\end{array}$ \\
\hline My school makes all students follow rules. & & & & & \\
\hline The school supports my individual learning needs. & & & & & \\
\hline Schoolwork is the same for everyone in my class. & & & & & \\
\hline $\begin{array}{l}\text { The school goes out of its way to celebrate mine anc } \\
\text { family's achievement, my culture and spirituality. }\end{array}$ & & & & & \\
\hline $\begin{array}{l}\text { My school communicates to my family land commur } \\
\text { what it stands for and how it works. }\end{array}$ & & & & & \\
\hline My schoolwork is useful to my life and to my family. & & & & & \\
\hline
\end{tabular}

Figure 3: Profiling tool items for the Category - Culture, as presented to students 


\section{Community}

Aboriginal and Torres Strait Island culture is evident in curriculum, policy and practice at our school. (a)

This school has a well developed and planned program of service learning. (b)

The school plans activities throughout school that link to relevant cultural activities and groups. (c)

The school develops planned programs to support students to reflect on their personal needs and those of the community.

The school makes best use of school and community resources for educational outcomes. (d)

The school plans programs that support the development of the school and community. (e)

School programs are available to support teachers, students and parents to build respectful relationships. (f)

Service learning is part of the curriculum and students are taught how to engage in reflective practice. $(\mathrm{g})$

The school carefully plans activities that are representative of a range of cultures. (h)

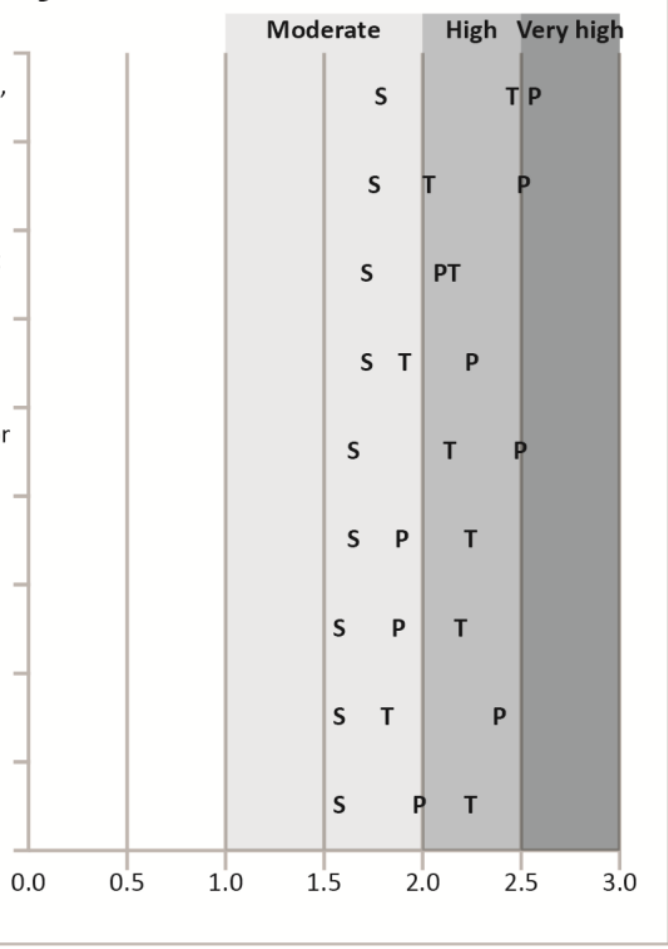

(a) Student perceptions differ from both parent and teacher perceptions. (b) Student perceptions differ from parent perceptions. (c) Student perceptions differ from both parent and teacher perceptions. (d) Student perceptions from both parent and teacher perceptions. (e), (f), (h) Teacher perceptions differ from student perceptions. (g) Student perceptions differ from parent perceptions.

Figure 4: Bar graph for the category 'community' using the teacher survey as a template. Note: $S=S$ Student Mean, $\mathrm{T}=$ Teacher Mean, $\mathrm{P}=$ Parent Mean. 


\section{The School Renewal Survey: Reflection}

The School Renewal Survey serves as a mirror to help your school community to reflect on who you are, where you are and where you want to go in terms of teaching young people. After reading the School Renewal Survey Report please list below 3 things that the survey has helped you to see that you do well in your school community, 3 things that the survey has helped you to see that you can immediately improve in your school community and 3 issues that the survey has helped you to see as challenges that your school community may embrace in the future.

\begin{tabular}{|l|l|l|}
\hline \multicolumn{1}{|c|}{ Pluses } & \multicolumn{1}{|c|}{ Minuses } & \multicolumn{1}{c|}{ Interesting } \\
(Three things we do well) & (Three things we can improve now) & (Three challenges for the future) \\
\hline 1. & 1. & 1. \\
3. & 2. & 3 \\
\hline
\end{tabular}

Question: Would you recommend that this survey be used by other School Communities in the school system? Please provide a reason/s for the above response:

Figure 5: School renewal reflection sheet 